\title{
TRENDS OF PRESCRIBING ANTIBIOTICS IN VARIOUS DENTAL DISEASES AT DIFFERENT PRIVATE CLINICAL SETUPS OF SIALKOT, PAKISTAN.
}

\footnotetext{
1. BDS, MSc Oral Pathology

Assistant Professor

Department of Oral Pathology Islam Dental College Sialkot.

2. BDS, MSc Oral Biology

Associate Professor and HOD Department of Oral Biology Islam Dental College, Sialkot.

3. M.D FCPS

Assistant Professor

Oral and Maxillofacial Surgery

Islam Dental College Sialkot.

4. BDS, MSc

Assistant Professor

Isra Medical and Dental College

5. Pharm.D, Ph.D

Assistant Professor

Faculty of Pharmacy

University of Sindh, Jamshoro.

6. Pharm.D, M.Phil

Lecturer

Faculty of Pharmacy

Ziauddin University, Karachi.
}

Correspondence Address:

Dr. Danish Javed

Department of Oral Pathology

Islam Dental College Sialkot.

sciencepk62@gmail.com

Article received on:

27/11/2018

Accepted for publication:

02/02/2019

Received after proof reading: $30 / 09 / 2019$

\begin{abstract}
Danish Javed', Sana Zafar², Shakeel Ahmad ${ }^{3}$, Khurram Anwar $^{4}$, Mudassar Iqbal Arain ${ }^{5}$,
\end{abstract} Saira Shahnaz ${ }^{6}$

ABSTRACT... Objectives: Antibiotics widely used now a day in dental practice for treatment of acute odontogenic, non-odontogenic infections and as a prophylactic purpose for focal infections in patients at possibility for infective endocarditis development as well as prevention of surgical infection of wound and controlling of orofacial infections. Studies of prescribing trends provide information about the quality \& pattern of use causes of drug use, and their outcomes. The main objective of this study was to assist trends and the rational utilization of antibiotics in dental practice. Study Design: Descriptive study. Settings: The current study was conducted among the different private dental clinical settings of Sialkot. Period: Eight months study (Jan-Aug 2018). Material and Methods: Sample size was 700 prescriptions which were gathered during. A purposive sampling was used for collection of prescription. A proforma was used for recording all required demographic \& prescribing data was designed to collect all information associated to antibiotic prescribing trend. The data was collected, compiled, \& analysed on MS Excel and descriptive statistics was used for analysing the result of the study. Results: A total of 700 prescriptions were collected from various Dental clinics. Among the study, $58.7 \%$ patients were male and $41.3 \%$ females and more frequent age group was 51-68 (37\%). Mostly patients have pervious medication history (38.8\%) and most common diagnosis was periodontal abscess (16.6\%) observed during our study followed by pulpitis (15.9\%). The trend observed was that majority $35.3 \%$ would prescribe antibiotics for patients who presented with elevated body temperature. Commonly 5 drugs per prescription prescribed (26.7\%) least numbers of drugs prescribed per prescription is $2(5.9 \%)$. Total 3445 drugs were prescribed in 700 prescriptions. Analgesics are frequently prescribed drug category $(22.3 \%)$ followed by antibiotics (21.8\%) Amoxicillin and clavulanic acid was mostly used (31.9\%) in these dental centres. Conclusion: This study show that most prevalent dental disease for which doctors prescribed antibacterial was periapical or periodontal abscess and Amoxicillin and clavulanic acid used as a $1^{\text {st }}$ choice for oral infections.

Key words: $\quad$ Orofacial Infections, Prophylactic, Odontogenic Infections.

Article Citation: Javed D, Zafar S, Ahmad S, Anwar K, Arain MI, Shahnaz S. Prescription trend of antibiotics among various dental diseases at different private clinical setups of Sialkot, Pakistan. Professional Med J 2019; 26(10):16181624. DOI: 10.29309/TPMJ/2019.26.10.1625

\section{INTRODUCTION}

The discovery and use of antibiotics has ward off many losses of lives, upgrade health care practice, and gave new directions to public health for various disease control. ${ }^{1}$

In dentistry, reasons for use of antibiotics are limited in dental practice but it should be used medical history or presence of comorbidities such as urinary tract infections, liver disease and presence of oral \& severity maxillofacial infection. The common cause of dental pain is infection induced inflammation. Dental infections are controlled by removal of the foci of infection. This is possible by removal of scaling, infected pulp \& drainage of the pus. It is supported, when proper anti inflammatory agents are used to relief the infection. ${ }^{2}$ Subsequently, dental \& periodontal diseases are coped by simple mediation \& oral hygiene procedures. ${ }^{3}$

Antibiotics widely used in treatment of acute odontogenic \& non-odontogenic infections. These are also used as a prophylactic purpose 
for focal infections in patients at possibility for infective endocarditis development as well as for local infections \& prevention of surgical infection of wounds. ${ }^{4,5}$ Antibiotics minimize the treat of bacterial infections to adjacent tissues but serious complications and development of antibacterial resistance implicate attention and exact indications for prescribing antibiotics. ${ }^{6}$

So, we can say that antibiotic usage in dentistry practice is an integral part and besides that increase of bacterial resistance, the trend of misuse and overuse of antimicrobial are reflected to increase difficulty in the public health care system. ${ }^{7}$ However, the previous studies show that irrational antibiotics practices by dental doctors due to many number of reasons going from lack of awareness to social factors. ${ }^{8-9}$ The rational prescribing practice is vital in dental practice, so a monitoring system and different studies related to prescribing trends are important. ${ }^{10-11}$ Therefore, this study was conducted to determined rational prescribing trends of antibiotics, as well-defined by the World Health Organization (WHO). ${ }^{12}$ This study, enable us to investigate the use of antibiotic in different dental problems which provide over view for evaluate the antibiotic utilization in prescriptions and extent the possessions of restrictive methods on the level of antibiotic practice..$^{13-16}$ Hence, such studies play a fundamental role in health care system.

Therefore the current study was conducted to determine the Prescription trend of Antibiotics among various dental diseases and main objective is to analyse prescribing habits and identify to ultimate misuses of antibiotics in different dental practices.

\section{METHODOLOGY}

A descriptive study was carried out in five different dental clinical settings of Sialkot, Punjab, Pakistan. A total of 700 prescriptions were randomly collected from study site during eight month (Jan-Aug 2018). Purposive sampling was used for collection of prescriptions. A proforma was used for recording all required demographic \& prescribing data and to collect information associated to the antibiotic prescribing trend for different oral pathologies and infections. All the patients with dental diseases who used antibiotics were included. The data was collected, compiled, \& analysed on MS Excel and descriptive statistics was used for analysing the result of the study.

\section{RESULTS}

Total 700 prescriptions were gathered during this study, in which male $58.7 \%$ were males and female were $41.3 \%$. (Table-I)

The majority of patients (37\%) were belonging to 50-60 age groups as shown in Table-II.

The majority of patients (37\%) were belonging to 50-60 age groups as shown in Table-II.

Further the study of prescriptions were analysed regarding the details of antibiotics prescription for medically compromised patients during scaling and tooth removal treatment. 311 patients out of 700 were afflicted with medical comorbidities, Hypertension (21\%) was the most prevalent comorbidity accounting of all dental patients as shown in Table-IV.

Table-V. shows the disease patterns in patients. Mostly periodontal abscess (16.6\%) was observed followed by pulpitis (15.9\%). Least number of subjects i.e. 23 (3.3\%), would have dry socket.

The trend observed was that majority $35.3 \%$ would prescribe antibiotics for patients who presented with elevated body temperature as shown in Table-IV.

Table-VII show that most frequently 5 drugs per prescription prescribed (26.7\%) least numbers of drugs prescribed per prescription is $2(5.9 \%)$.

Table-VIII shows that analgesics (22.3\%) was mostly prescribed drug to the relieve the pain followed by antibiotics (21.8\%).

Table-IX shows Antibiotics prescribing trends in patients, mostly Amoxicillin and clavulanic acid was used $(32.9 \%)$ during our study, followed by Chlorhexidine $31.8 \%$. 


\begin{tabular}{|l|c|c|}
\hline \multicolumn{1}{|c|}{ Gender } & No. of Patients & Percentage \\
\hline Male & 411 & $58.7 \%$ \\
\hline Female & 289 & $41.3 \%$ \\
\hline Total & 700 & $100 \%$ \\
\hline
\end{tabular}

Table-I. Gender wise distribution

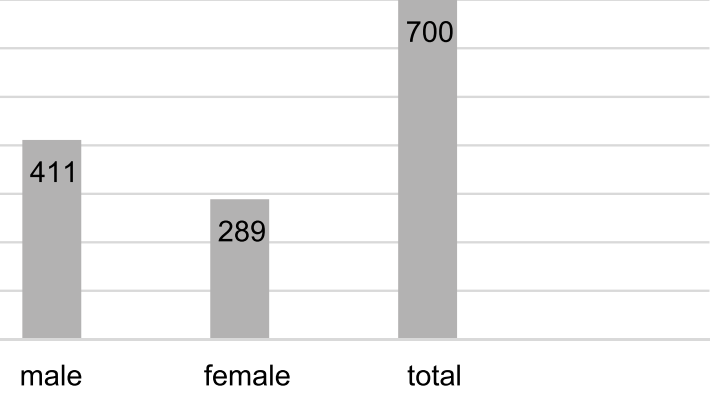

Figure-1. Gender wise distribution

\begin{tabular}{|l|c|c|}
\hline \multicolumn{1}{|c|}{ Age Groups } & No. of Patients & Percentage \\
\hline Less than 10 years & 107 & $15.3 \%$ \\
\hline $11-20$ & 41 & $5.9 \%$ \\
\hline $21-30$ & 40 & $5.7 \%$ \\
\hline $31-40$ & 63 & $9 \%$ \\
\hline $41-50$ & 103 & $14.7 \%$ \\
\hline $51-60$ & 259 & $37 \%$ \\
\hline$>61$ & 87 & $12.4 \%$ \\
\hline Total & 700 & $100 \%$ \\
\hline
\end{tabular}

Table-II. Age wise distribution

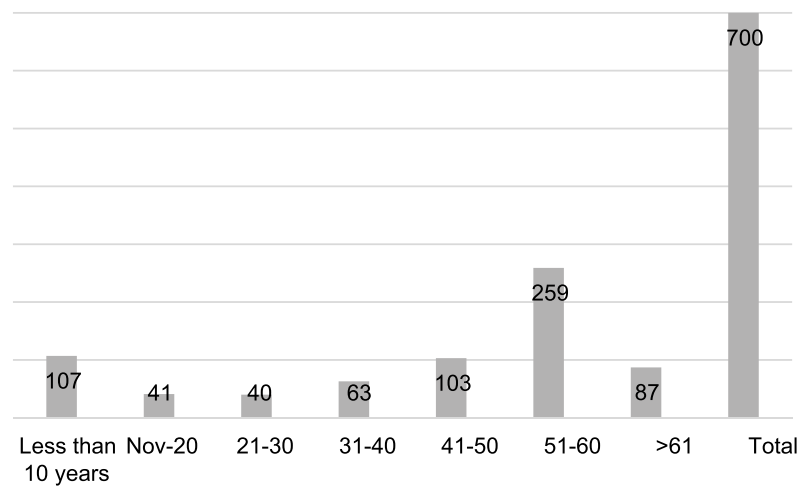

Figure-2. Age wise distribution

\begin{tabular}{|l|c|c|}
\hline Medical History & No. of Patients & Percentage \\
\hline Yes & 272 & $38.9 \%$ \\
\hline No & 157 & $22.4 \%$ \\
\hline Not mentioned & 271 & $38.7 \%$ \\
\hline Total & 700 & $100 \%$ \\
\hline
\end{tabular}

Table-III. Pervious medical history of patients

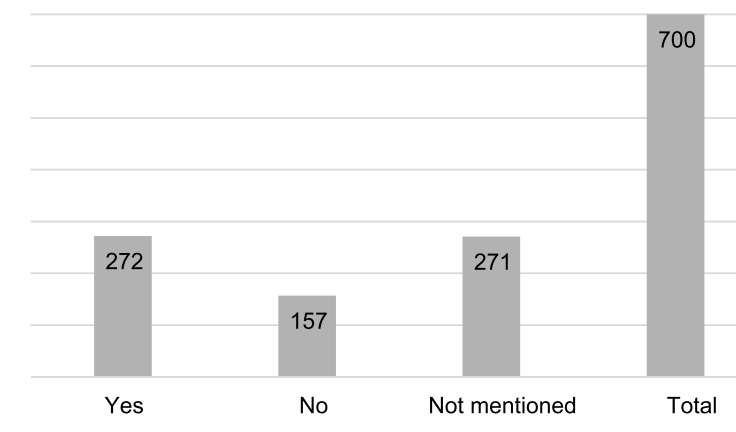

Figure-3. Medical history of patients

\begin{tabular}{|l|c|c|}
\hline \multicolumn{1}{|c|}{ Diseases } & $\begin{array}{c}\text { No of Patients } \\
(\mathbf{n = 7 0 0 )}\end{array}$ & Percentage \\
\hline Hypertension & 147 & $21 \%$ \\
\hline Diabetes mellitus & 81 & $11.6 \%$ \\
\hline Cardiovascular diseases & 42 & $6 \%$ \\
\hline Liver disease & 29 & $4.1 \%$ \\
\hline Urinary tract infection & 12 & $1.7 \%$ \\
\hline \multicolumn{2}{|c|}{ Table-IV. Frequency of co morbidities } \\
\hline
\end{tabular}

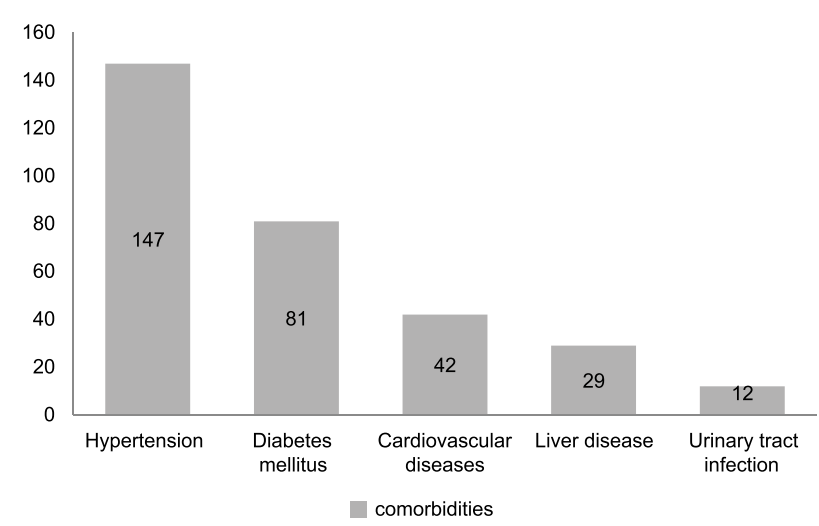

Figure-4. Diagnosis for Which antibiotic were described

\begin{tabular}{|l|c|c|}
\hline \multicolumn{1}{|c|}{ Clinical Diagnosis } & $\begin{array}{c}\text { No. of } \\
\text { Patients }\end{array}$ & Percentage \\
\hline Acute periapical infection & 98 & $14 \%$ \\
\hline Pulpitis & 111 & $15.9 \%$ \\
\hline Chronic periodontitis & 103 & $14.7 \%$ \\
\hline $\begin{array}{l}\text { Periapical or periodontal } \\
\text { abscess }\end{array}$ & 116 & $16.6 \%$ \\
\hline Acute inflammation & 92 & $13.1 \%$ \\
\hline Dry socket & 23 & $3.3 \%$ \\
\hline Implant placement & 45 & $6.4 \%$ \\
\hline $\begin{array}{l}\text { Inflammation of the sublingual } \\
\text { gland }\end{array}$ & 49 & $7 \%$ \\
\hline Fracture of teeth & 63 & $9 \%$ \\
\hline Total & 700 & $100 \%$ \\
\hline \multicolumn{2}{|c|}{ Table-V. Diagnoses for which antibiotics were } \\
prescribed
\end{tabular}




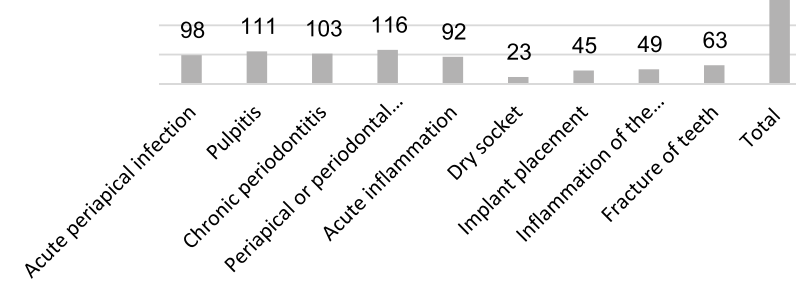

Series 1

Figure-5. Diagnoses for which antibiotics were prescribed

\begin{tabular}{|c|c|c|}
\hline Clinical Symptoms & $\begin{array}{l}\text { No. of } \\
\text { Patients }\end{array}$ & Percentage \\
\hline $\begin{array}{l}\text { Elevated temperature and } \\
\text { systemic spread }\end{array}$ & 247 & $35.3 \%$ \\
\hline Localized fluctuant swelling & 160 & $22.8 \%$ \\
\hline Gross/diffuse swelling & 118 & $16.9 \%$ \\
\hline Restricted mouth opening & 90 & $12.9 \%$ \\
\hline Difficulty in swallowing & 85 & $12.1 \%$ \\
\hline Total & 700 & $100 \%$ \\
\hline
\end{tabular}

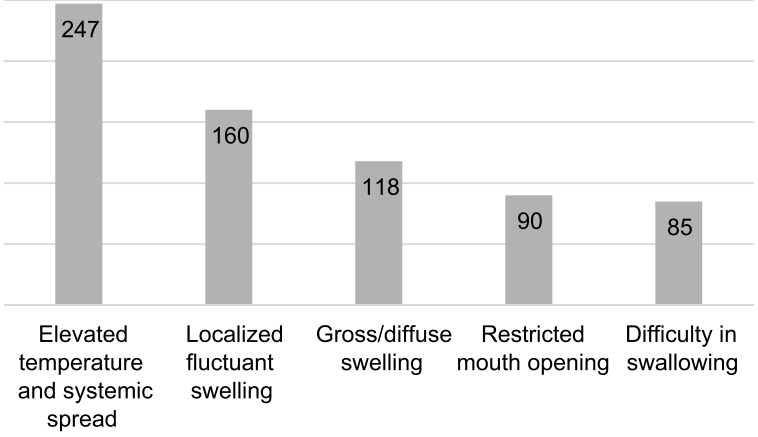

Figure-6. Distribution of antibiotics prescribing for various clinical symptoms

\begin{tabular}{|c|c|c|}
\hline No. of Drugs & No. of Prescriptions & Percentage \\
\hline 2 & 41 & $5.9 \%$ \\
\hline 3 & 84 & $12 \%$ \\
\hline 4 & 123 & $17.6 \%$ \\
\hline 5 & 187 & $26.7 \%$ \\
\hline 6 & 171 & $24.4 \%$ \\
\hline 77 & 94 & $13.4 \%$ \\
\hline Total & 700 & $100 \%$ \\
\hline Table-VII. Number of drugs prescribed in per \\
\hline \multicolumn{2}{|c|}{\begin{tabular}{c} 
prescription \\
\hline
\end{tabular}} \\
\hline
\end{tabular}

Professional Med J 2019;26(10):1618-1624.

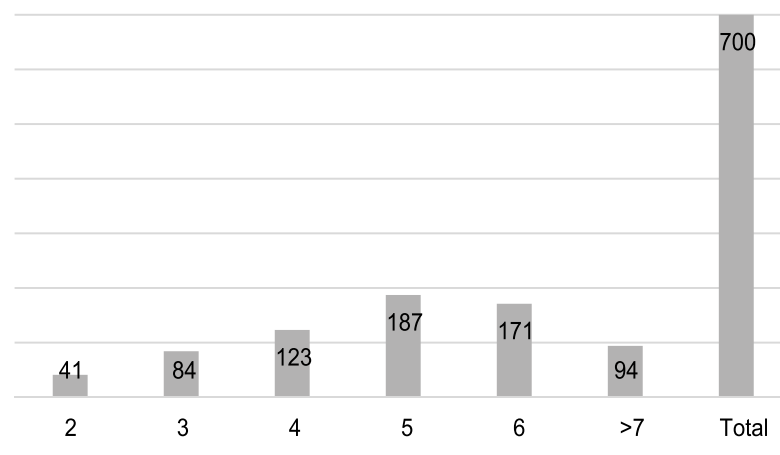

Figure-7. Number of drugs per prescription

\begin{tabular}{|l|c|c|}
\hline \multicolumn{1}{|c|}{ Name of Category } & No of Drug & Percentage \\
\hline Antibiotics & 751 & $21.8 \%$ \\
\hline Analgesics & 767 & $22.3 \%$ \\
\hline Anesthetics & 572 & $16.6 \%$ \\
\hline Antifungals & 431 & $12.5 \%$ \\
\hline Antiseptics & 663 & $19.2 \%$ \\
\hline Miscellaneous Drugs & 261 & $7.6 \%$ \\
\hline Total & 3445 & $100 \%$ \\
\hline \multicolumn{2}{|c|}{ Table-VIII. Prescribing frequency of different drug } \\
categories
\end{tabular}

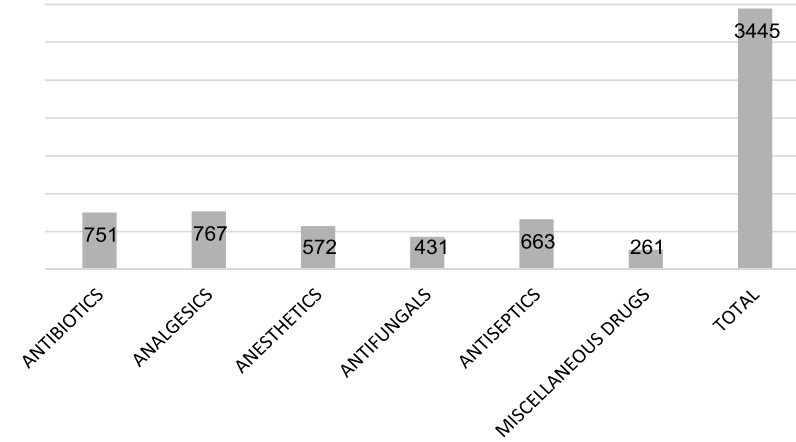

Figure-8. Prescribing frequency of different drug categories

\begin{tabular}{|l|c|c|}
\hline \multicolumn{1}{|c|}{ Drugs Name } & No. of Drugs & Percentage \\
\hline $\begin{array}{l}\text { Amoxicillin and } \\
\text { clavulanic acid }\end{array}$ & 247 & $32.9 \%$ \\
\hline Chlorhexidine & 239 & $31.8 \%$ \\
\hline Ciprofloxacin & 121 & $16.1 \%$ \\
\hline Azithromycin & 63 & $8.4 \%$ \\
\hline Amoxicillin & 21 & $2.8 \%$ \\
\hline Cefuroxime & 60 & $8 \%$ \\
\hline Total & 751 & $100 \%$ \\
\hline \multicolumn{1}{|c|}{ Table-IX. Frequently prescribed antibiotics: } \\
\hline
\end{tabular}




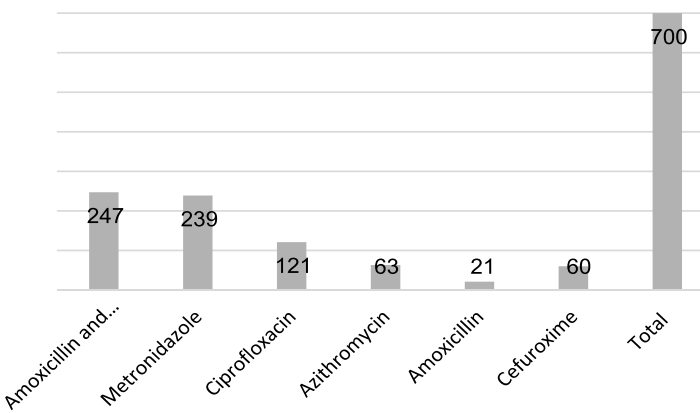

Figure-9. Prescribing trends of antibiotics

\begin{tabular}{|l|c|c|}
\hline Dosage Forms & $\begin{array}{c}\text { No. of Patients } \\
\text { (700) }\end{array}$ & Percentage \\
\hline Tables & 687 & $98.3 \%$ \\
\hline Ointments & 552 & $78.9 \%$ \\
\hline Injections & 339 & $48.2 \%$ \\
\hline Capsules & 109 & $15.6 \%$ \\
\hline \multicolumn{2}{|r|}{ Table-X. Frequency of dosage forms } \\
\hline \multicolumn{2}{|r}{} \\
\hline
\end{tabular}

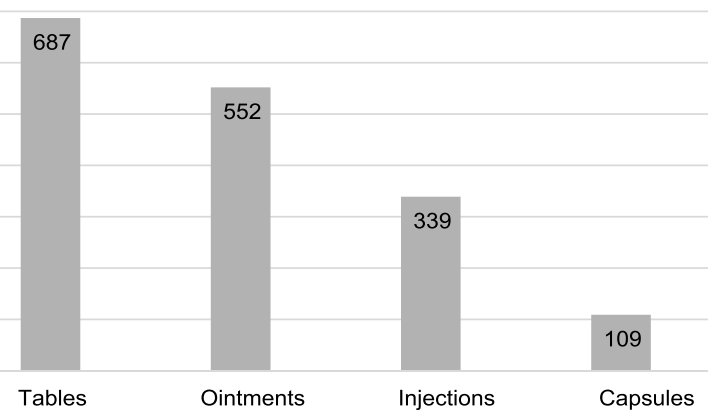

Figure-10. Frequency of different dosage forms

\section{DISCUSSION}

This study evaluated the trends of antibiotic prescribing among dentists practice in various private dental clinical setups of Sialkot, Pakistan. Studies of prescribing trends provide information about the quality, pattern and causes of drug use and their outcomes. The main purpose is to assist the utilization trends of antibiotics in dental practice in Sialkot because Antibiotics play central role of being additions in the controlling of bacteraemia and orofacial infections.

A total of 700 prescriptions were collected from various Dental clinics. Among the study, 58.7\% patients were male and $41.3 \%$ females which show dental problem more common in males. The age group (50-60 years) of dental patients who were mostly $(37 \%)$ afflicted with dental problems.

Overall antibacterial prescription for endodontic conditions was high during this study. Amoxicillin and clavulanic acid remained the $1^{\text {st }}$ choice for treatment. The combination of Amoxicillin and Clavulanic acid or amoxicillin alone use for same indications because this combination is effective against Klebsiella bacteria and anaerobes. Amoxicillin have a wide range with low occurrence of resistance and profile of tolerance \& dosage, as similar to Pavan kumar et al study described that a combine treatment of Amoxicillin is most frequently $(30 \%)$ prescribed drug due to its wide spectrum of act on of Amoxicillin with least side effects. ${ }^{15,17-20}$

311 patients out of 700 were afflicted with medical comorbidities, Hypertension (21\%) was the most prevalent comorbidity accounting of all dental patients followed by diabetes mellitus (11.6) and cardiovascular diseases (6\%). Many previous research studies like Smeets et al.,${ }^{21}$ and Jainkittivong et al., (33.7\%) ${ }^{22}$ showed that most common medically compromised conditions were cardiovascular diseases in dental patients.

The most prevalent dental disease for which doctors prescribed antibacterial was periapical or periodontal abscess (16.6\%). which is similar to the results obtained by Palmer et al study also show that periodontal abscess is more common dental disease in which antibiotis were prescribed. ${ }^{23}$ The reasons for prescribing antibiotics was Prophylaxis, bacterial endocarditis, and dental implant. The next common finding for which antibiotics were prescribed were pulpitis (15.9\%), Chronic periodontitis in 103 patients (14.7\%), Acute periapical infection (14\%), which is different to the results obtained by Tong et al ${ }^{24}$ and Steed et $\mathrm{a}^{25}$, these were not indications for antibacterial prescribing. It has been generally accepted that pulpitis treatment with antibiotic is inappropriate ${ }^{26}$ because pulpitis is an inflammatory process \& only the local therapy can relieve pain and 
infection. An elevated temperature was observed in (35.3\%) patients. Short duration of analgesics are used for Dental management of pain. $2^{\text {nd }}$ most common prescribed drug category is antibiotics Analgesics are the most prescribing drug category (32.9\%) because it is used for toothache or pain following dental therapy as well as fever which increase the body temperature. The next common prescribed drug category was antibiotics(31.8\%)Out of the endodontic conditions necessitating antibiotic therapy mostly of the study patients prescribed by antibiotics for Periapical or periodontal abscess swelling present moderate pre- operative symptoms a parallel outcomes were got by Pavan kumar et al. (92.1\%), Yingling et al, Rodriguez et al (87-92\%).

Oral medications more frequently prescribed in these dental centres. Also polypharmacy is more common in the dental practice due to comorbid illnesses \& may be possible changes in normal physiology. However, Dentists must be cautious in prescribing of antibiotics for liver disease patients as shown in results because most of the medicines metabolize in this organ, so prescribing antibiotics for these patients should be carefully. Making awareness among dentists and patients is of utmost prominence and educational interventions to encourage the appropriate use of antibiotics in dentistry can be prepared at the local and national level.

\section{CONCLUSION}

This study shows that most prevalent dental disease for which doctors prescribed antibacterial was periapical or periodontal abscess and Amoxicillin and clavulanic acid used as a $1^{\text {st }}$ choice for oral infections. However, some of the probable descriptions can be inadequate understanding of pathological developments in the periapical area \& absence of knowledge about common signs for the current use of medicines. Antibiotics are a valuable drug for the management of bacterial or orofacial infections but increase in microbial resistance is a serious global problem, and overuse of antibiotics in dental care system can intensify it.

Copyright@ 02 Feb, 2019.

\section{REFERENCES}

1. British Infection Association. Management of infection guidance for primary care for consultation and local adaptation [Internet]. [cited 18 oct 31]. Available from: http://www.hpa.org.uk/webc/hpawebfile/ hpaweb_c/1194947333801.

2. https://www.researchgate.net/publication/266968828 A review of use of antibiotics in dentistry and recommendations for rational antibiotic usage by dentists [accessed Jan 06 2019].

3. Tong DC, Rothwell BR. Antibiotic prophylaxis in dentistry: A review and practice recommendations. J Am Dent Assoc. 2000 Mar; 131(3):366-74.

4. Sweeney LC, Dave J, Chambers PA, Heritage J. Antibiotic resistance in general dental practice a cause for concern? J Antimicrob Chemother. 2004 Apr; 53(4):567-7.

5. Poveda Roda R, Bagan JV, Sanchis Bielsa JM, Carbonell Pastor E. Antibiotic use in dental practice. A review. Med Oral Patol Oral Cir Bucal. 2007 May 1; 12(3):E18692.

6. Epstein JB, Chong S, Le ND. A survey of antibiotic use in dentistry. J Am Dent Assoc. 2000 Nov; 131(11):16009.

7. Steed M, Gibson J. An audit of antibiotic prescribing in general dental practice. Prim Dent Care. 1997 May; 4(2):66-70.

8. Segura-Egea JJ, Velasco-Ortega E, Torres-Lagares D, Velasco-Ponferrada MC, Monsalve-Guil L, LlamasCarreras JM. Pattern of antibiotic prescription in the management of endodontic infections amongst Spanish oral surgeons. Int Endod J. 2010 Apr; 43(4):342-5.

9. Gossens H. Antibiotic consumption and link to resistance. Clinical Microbiology and Infection. 2009; 15: $12-15$.

10. Cantón R, Horcajada JP, Oliver A, Garbajosa PR, Vila $J$. Inappropriate use of antibiotics in hospitals: the complex relationship between antibiotic use and antimicrobial resistance. Enfermedades Infecciosas y Microbiología Clínica. 2013; 31: 3-11.

11. World Health Organization (WHO). The role of education in the rational use of medicines, SEARO Technical Publication series No.54. India, 2006.

12. Finch R. Antibiotic Resistance-from pathogen to disease surveillance. Clinical Monitoring and infection. 2002; 8: 317-322. 
13. World Health Organization (WHO). The World Medicines Situation 2011 - Rational Use of Medicines. Geneva, 2011.

14. Schmidt-Mende K, Hasselstrom J. Drug utilization review--a practical example from primary care. Lakartidningen. 2013; 110: 1105-110.

15. Kumar KP, Kaushik M, Kumar PU, Reddy MS, Prashar $\mathrm{N}$. Antibiotic prescribing habits of dental surgeons in Hyderabad City, India, for pulpal and periapical pathologies: a survey. Advances in pharmacological sciences. 2013;2013.

16. Salako N, Rotimi VO, Adib SM, Al-Mutawa S. Pattern of antibiotic prescription in the management of oral diseases among dentists in Kuwait. J Dent. 2004; 32:503-509.

17. N. M. Yingling, B. E. Byrne, and G. R. Hartwell, "Antibiotic use by members of the American Association of Endodontists in the year 2000: report of a national survey," Journal of Endodontics, 2002; 28(5):396-404.

18. Rodriguez-N'ũnez, R. Cisneros-Cabello, E. VelascoOrtega,J. M. Llamas-Carreras, D. T'orresLagares, and J. J. Segura-Egea, "Antibiotic use by members of the Spanish endodontic society, "Journal of Endodontics, 2009;vol. 35, no. 9, pp. 1198-1203.

19. Vessal G, Khabiri A, Mirkhani H, Cookson BD, Askarian $M$. Study of antibiotic prescribing among dental practitioners in Shiraz, Islamic Republic of Iran. East Mediterr Health J 2011; 17: 763-769.
20. Smeets EC, de Jong KJ, Abraham-Inpijn L. Detecting the Medically Compromised Patient in Dentistry by Means of the Medical Risk-Related History: A Survey of 29,424 Dental Patients in the Netherlands. Preventive medicine. 1998 Jul 1;27(4):530-5.

21. Jainkittivong A, Aneksuk V, Langlais RP. Medical health and medication use in elderly dental patients. J Contemp Dent Pract. 2004 Feb 15;5(1):31-41.

22. Palmer NA, Dailey YM, Martin MV. Can audit improve antibiotic prescribing in general dental practice? $\mathrm{Br}$ Dent J. 2001 Sep 8; 191(5):253-5.

23. Tong DC, Rothwell BR. Antibiotic prophylaxis in dentistry: A review and practice recommendations. J Am Dent Assoc. 2000 Mar; 131 (3):366-74.

24. Steed M, Gibson J. An audit of antibiotic prescribing in general dental practice. Prim Dent Care. 1997 May; 4(2):66-70.

25. Dailey YM, Martin MV. Are antibiotics being used appropriately for emergency dental treatment? $\mathrm{Br}$ Dent J. 2001 Oct 13; 191(7):391-3.

26. Piñeiro A, Tomás I, Blanco J, Alvarez M, Seoane J, Diz P. Bacteraemia following dental implants' placement. Clin Oral Implants Res. 2010 Sep; 21(9):913-8.

\begin{tabular}{|c|c|c|c|}
\hline \multicolumn{4}{|c|}{ AUTHORSHIP AND CONTRIBUTION DECLARATION } \\
\hline Sr. \# & Author-s Full Name & Contribution to the paper & Author's Signature \\
\hline 1 & Danish Javed & Concept \& Writing. & \\
\hline 2 & Sana Zafar & Data collection. & \\
\hline 3 & Shakeel Ahmad & Descriptive analysis. & \\
\hline 4 & Khurram Anwar & Data collection. & \\
\hline 5 & Mudassar lqbal Arain & Proof reading. & \\
\hline 6 & Saira Shahnaz & Proof reading. & Qaits \\
\hline
\end{tabular}

